\title{
Not All About Farming: Understanding Aspirations Can Challenge Assumptions About Rural Development
}

\author{
Kai Mausch ${ }^{1}$ D $\cdot$ Dave Harris $^{2,3} \cdot$ Luke Dilley $^{1,4} \cdot$ Mary Crossland $^{3}$ (D) \\ Tim Pagella ${ }^{3} \cdot$ Jules Yim $^{5} \cdot$ Emma Jones $^{5}$
}

Accepted: 20 March 2021 / Published online: 15 April 2021

(c) The Author(s) 2021

\begin{abstract}
Rural development is a political topic in which debate has been more focussed on externally identified needs than on demands or aspirations of the rural population and polarised between the attractions of urban income earning opportunities and the importance of rural farming communities for national food provision. The heterogeneity of local aspirations and their implications for development have barely been considered. We explore the aspirations of residents of three contrasting regions in Kenya that vary in their agricultural and off-farm potential. We argue that opportunities are a major framing influence on aspirations but there is important, and routinely overlooked, diversity within the communities which could inform future options for effective development. We outline how development initiatives could be redesigned to align more closely with aspirations. However, aspirations are a complex concept and, while our approach offered novel insights, these would be enriched when combined with household survey data.
\end{abstract}

Keywords Livelihoods $\cdot$ Kenya $\cdot$ Project design $\cdot$ Diversity $\cdot$ Farming $\cdot$ Off-farm employment $\cdot$ Incomes $\cdot$ SenseMaker®

Kai Mausch

K.Mausch@cgiar.org

1 World Agroforestry (ICRAF), United Nations Avenue, PO Box 30677-00100, Gigiri, Nairobi, Kenya

2 International Crops Research Institute for the Semi-Arid Tropics (ICRISAT), PO Box: 39063, Nairobi, Kenya

3 School of Natural Sciences, Bangor University, Bangor, Gwynedd LL57 2UW, UK

4 Global Studies Program, Faculty of International Liberal Arts, Akita International University, Yuwa, Akita-City 010-1292, Japan

5 Cognitive Edge, 1 Raffles Place, \#20-61 Tower 2, Singapore 048616, Singapore 


\section{Résumé}

Le développement rural est un sujet politique dont le débat s'est plus focalisé sur les besoins identifiés de l'extérieur, plutôt que sur les demandes ou aspirations de la population rurale. Ce débat s'est polarisé entre les attraits d'opportunités de revenus urbains et l'importance des communautés rurales agricoles pour nourrir la nation. L'hétérogénéité des aspirations locales et ce que cela implique pour le développement ont été peu considérés. Nous explorons les aspirations des habitants de trois régions contrastées du Kenya, qui varient de par leur potentiel agricole et hors agriculture. Nous estimons que les opportunités de revenus ont une influence majeure sur les aspirations des individus, mais il y a une importante diversité, et souvent négligée, entre les communautés, qui pourrait guider les options futures de développement. Nous soulignons comment les initiatives de développement pourraient être redéfinies pour mieux s'aligner sur ces aspirations locales. Cependant, les aspirations sont un concept complexe et, alors que notre approche a révélé de nouvelles idées sur la question, ces conclusions seraient plus complètes si l'étude combinait des données d'enquêtes sur les ménages.

Mots-clés Moyens de subsistance $\cdot$ Kenya $\cdot$ conception de projet $\cdot$ diversité . agriculture $\cdot$ emploi non agricole $\cdot$ revenus $\cdot$ SenseMaker®

\section{Introduction}

Most of the global poor live in rural areas that have been a substantial focus of development efforts over the last 70 years. While there have been significant shifts in the discourse and practice of rural development since the 1950s, Ellis and Biggs (2001) note the emergence of the concept of 'sustainable livelihoods' as a central motif in more recent development approaches. For Ellis and Biggs (2001, p. 445), the concept of sustainable livelihoods potentially enables a move away from the previous 'farming first' mentality as it "embodies no prior requirement for the poor rural individual or family to be a "small farmer'" (see also Scoones 2009). The importance of recognising the diversity of livelihood strategies in rural areas has been underscored by evidence of the increasing income diversification among those who farm (Barrett et al. 2001) and the importance of migration to urban centres by rural residents (Mercandalli et al. 2020). Such evidence has raised questions about whether traditional rural development approaches that primarily seek to improve agricultural production are suitable for rural populations whose non-farm activities are becoming increasingly important for their livelihoods and potentially reduce their commitment to farming (Kihoro et al. 2021; Rigg 2006). This leads to further questions about what those living in rural areas, if they are not committed to farming, might want to do. However, while a recognition of the diversity of livelihood strategies within rural development approaches may be an important step, the policy and practice of rural development still often fails to engage with what rural residents want to do, or rather what they aspire to do. 
The increasing importance of non-farm activities for rural livelihoods has already led to questions over the attractiveness of technological agricultural solutions (e.g. Llewellyn and Brown 2020). A growing concern over the potential for rural smallholder farmers to 'farm themselves out of poverty' (Gassner et al. 2019; Harris and Orr 2014) also suggests the need to re-think the agricultural focus of many development efforts. It is in this context that we see aspirations playing a potentially significant role in the redesign of rural development efforts. In this study, we define aspirations as envisioned future livelihood strategies and their associated income components (Mausch et al. 2018). This includes a recognition that sometimes income streams may be based on necessity rather than choice and thereby aspirations are not necessarily visions of likely future states but rather "an orientation towards a desired future" (Huijsmans et al. 2020, p. 3). Arguably, supporting the aspirations of rural people, enabling them to take a step closer to doing what they want to do (be it agricultural or not), will lead to more efficient development efforts. Those who want to move out of agriculture could do so, leaving others to benefit from agricultural intervention and so produce the food required to feed the population. It is the distinct recognition that it is not purely outside forces that push people out of agriculture or force them to remain but rather agricultural and non-agricultural aspirations need to be understood as desired shifts in livelihoods (Bennike et al. 2020). We build on recent studies (Mausch et al. 2018; Verkaart et al. 2018) that began to investigate aspirations and their implications for the design of support mechanisms and explored aspirations against potential entry points for agricultural development efforts.

In contrast to recent studies that use an aspiration index (Bernard and Taffesse 2014), we aim to capture the full scope of aspirations in a way that does not restrict the expression of respondents. While the aspiration index captures ambitions, it focuses on the relative status of respondents within the community today and in the future; it does not capture the direction of any change with respect to income sources and thereby cannot support new approaches to rural development and targeting of interventions.

In this paper we explore the diversity of farm and non-farm related aspirations across a cross-section of rural Kenyan communities. We use a narrative-based approach in which respondents interpret their own aspirational stories using predefined livelihood-based assessment questions. We highlight implications and potential strategies for agricultural support mechanisms and incorporation of these into broader development efforts. Furthermore, we focus on differences between contrasting regions to explore the degree to which context informs aspirations. Finally, we discuss implications for the redesign of development approaches.

\section{Theoretical framework}

The livelihood concept (Scoones 2009) outlines how a household's assets and political and institutional factors shape their options for taking decisions about their livelihood strategies and income structure. The concept is, therefore, well suited to the assessment of peoples' aspirations. Rural households that farm in sub-Saharan 
Africa mostly operate on small land parcels which limits their potential to earn substantial incomes from agriculture (Gassner et al. 2019; Harris 2019; Harris and Orr 2014). Consequently, their livelihood portfolios have become increasingly diverse (Ellis and Freeman 2004; Haggblade et al. 2010) and it is unclear which actual and potential income streams drive household choices. In practice, livelihood strategies are often fluid and have rather 'fuzzy' boundaries between different income streams, yet explicit consideration of the preferred means and direction of travel towards prosperity is seldom included in surveys.

Better understanding of households' aspirations could offer a solution. It is argued that aspirations moderate responses to incentive structures and thereby influence choices among potential options (Mausch et al. 2018; Verkaart et al. 2018). Yet, aspirations are not purely shaped by individual desires (Huijsmans et al. 2020). Social pressures, norms and expectations also play a role in their formation and expression (Bennike et al. 2020; Crossland et al. 2021). For example, in many communities 'farming' is not only an income generation activity but is also perceived as a lifestyle. This is despite the fact that income portfolios are increasingly dominated by sources outside farming (Borras et al. 2008; Verkaart et al. 2018). It is therefore important to capture the full scope of aspirations and not to restrict the respondents to aspirations related to any particular income stream-even when the goal is to identify potential entry points for agricultural development. ${ }^{1}$

Figure 1 summarises the framework at the core of this study. Besides the recognition of the context within which aspirations are formed (here light grey), there are further limits and biases that need to be considered. Galiani et al. (2018) highlight that aspirations beyond achievable outcomes can lead to adverse outcomes as people become discouraged. Therefore, considering the 'adjacent possible' ${ }^{2}$ (here mid grey) by providing options that recognise viable aspirations should be more likely to improve development outcomes. Theoretically, the adjacent possible narrows the context (here light grey) within which aspirations are formed. In the longer term, aspirations could, however, go beyond the adjacent possible when multiple intermediate steps are envisioned towards the aspired future.

In addition to the contextual conditions and the adjacent possible that shape the options people can pursue, human behaviour and the resulting limitation of information processing and choice-making (World Bank 2015) shape aspiration formation and the 'aspiration window'. The aspiration window (here dark grey) can be described as imaginable futures based on observations of peers and evolves through social interactions (Appadurai 2004; Dilley et al. 2021; Ray 2006) and through this interaction it can change or widen (Macours and Vakis 2014). The aspiration window does not necessarily align with real options as biases and imagination influence its size and shapes "what individuals perceive as desirable, possible, or even 'thinkable' for their lives" (World

\footnotetext{
1 Therefore, we do not explicitly focus on any distinct pathway or strategy but aim to capture any strategy be it agriculture, off-farm employment or self-employed businesses. It is only in our interpretation where we focus on the agricultural contributions and its role in supporting the pursuit of aspirations.

2 The "adjacent possible consists of all things that are one step away from what already exists" (Monechi et al. 2017, p. 3). The concept highlights the limitations as well as the creative potential to change by describing potential future states in relation to current conditions (Kauffman 1996).
} 


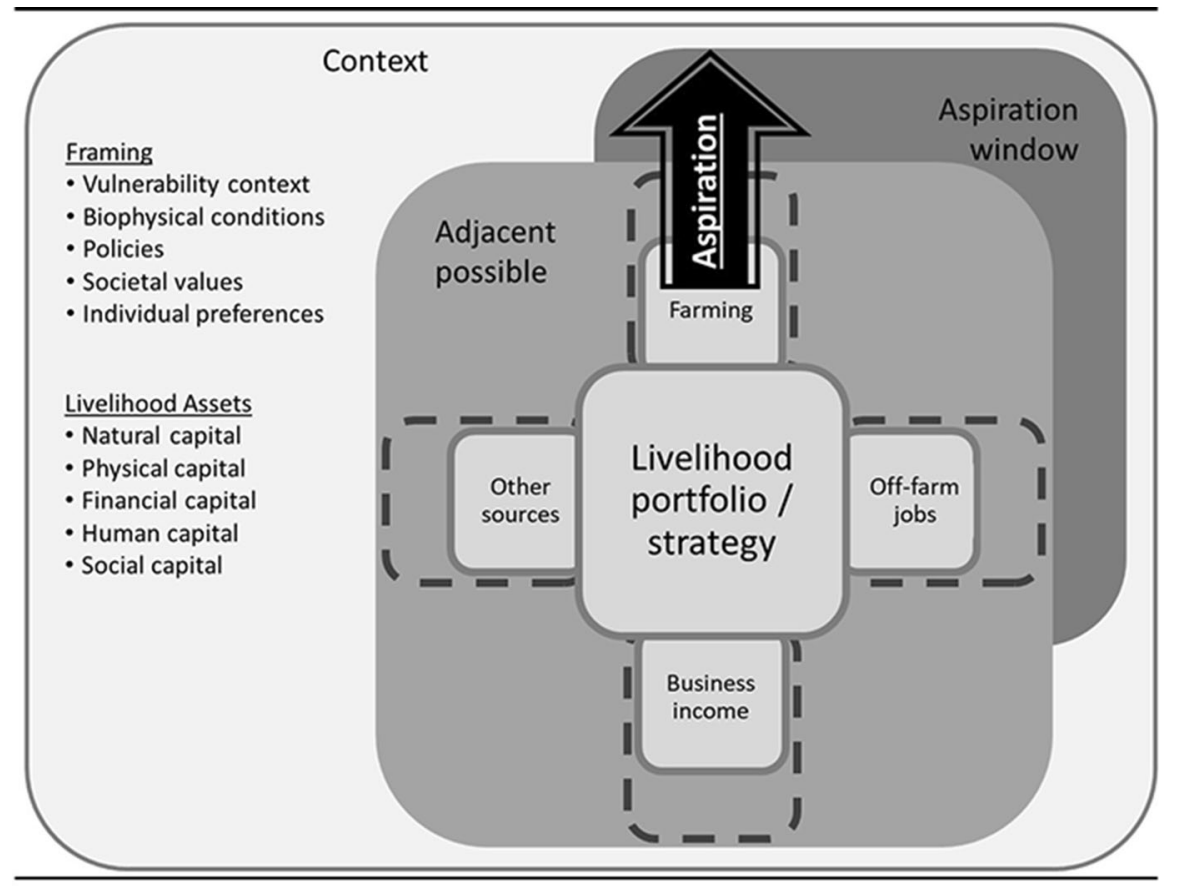

Note: The livelihood assets and the framing of outside factors such as biophysical factors, policies and values provide the context within which aspirations are formed (ight grey). Within the adjacent possible space (mid grev) changes in the current livelihood strategy can be made (dashed line). The aspiration window (dark grey) represents the restricted individual view of the options space.

Fig. 1 Aspirational pursuit and influences

Bank 2015, p. 3). It may even be smaller than the adjacent possible based on biases in perception.

Despite a growing recognition of the importance of considering aspirations in the recent literature, there is no consensus on how to assess, measure and interpret them. Bennike et al. (2020), for example, highlight the need to analyse aspirations beyond the individualised view. They critique the implicit blaming of people's lack of aspirations by focussing on the factors that influence or hinder aspirational pursuit. Explicit consideration of people's and communities' aspirations provides both an entry point as well as a mechanism to evaluate outcomes of development interventions. 


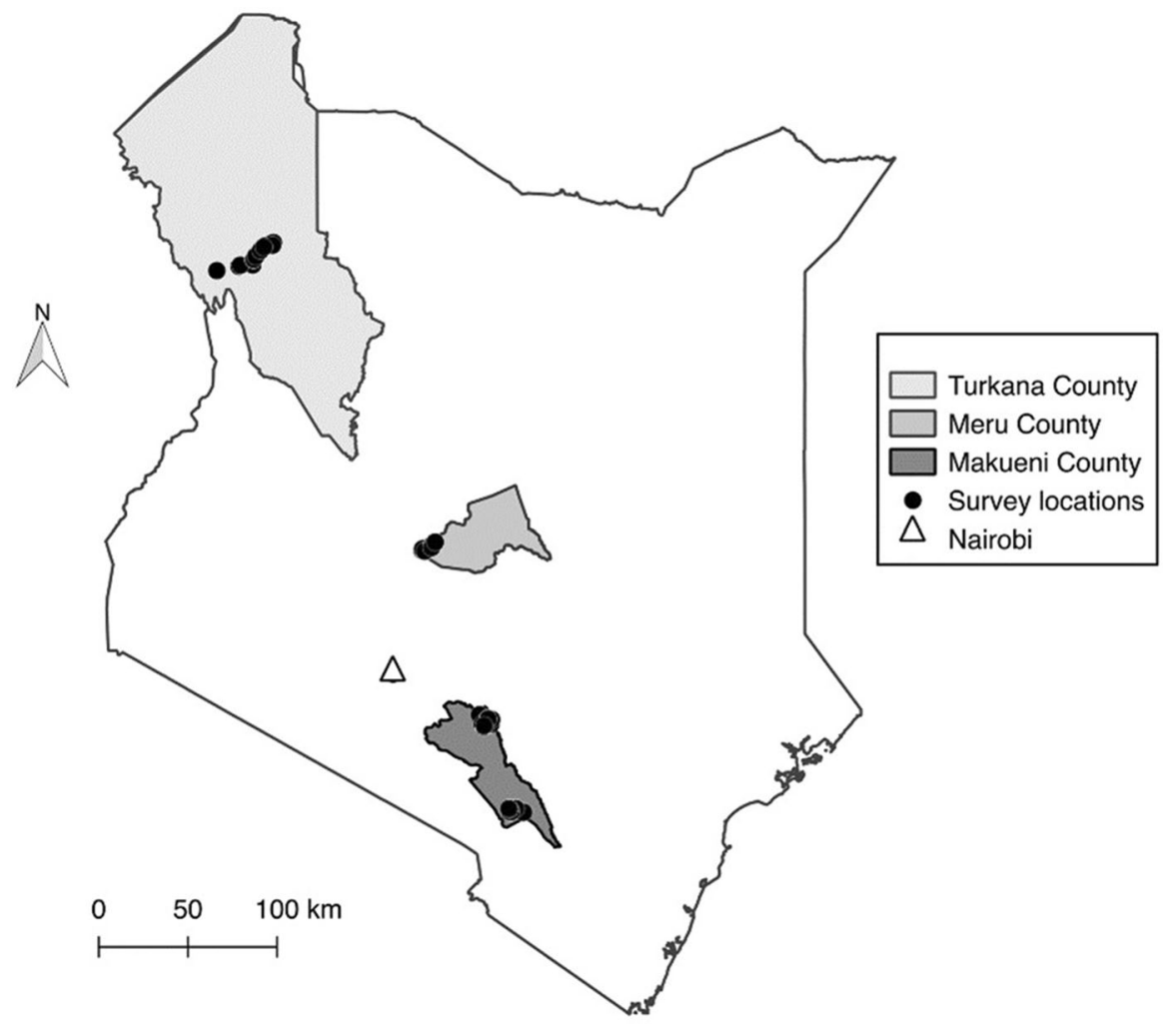

Fig. 2 Study sites and survey locations

\section{Methods}

\section{Research sites and sampling}

We selected three research sites in rural Kenya with different levels of agricultural potential and off-farm employment opportunities-Turkana, Meru and Makueni counties (Fig. 2).

These three counties were purposively selected as they represent the range of diversity within the country and vary in their distance and connectivity to urban centres and in their agro-ecological potential. Turkana is a remote region of Kenya with low rainfall, limited agricultural potential and a predominantly migratory, pastoral lifestyle. Food insecurity episodes are frequent and there are few non-agricultural opportunities (Turkana County Government, n.d). Makueni is characterised by small-scale, rainfed farming with frequent crop failures due to unreliable rainfall (Makueni County Government, 2013). Livestock keeping alongside food crop production are common agricultural activities in Makueni and there is some wage employment (GOK and FAO, 2014). Meru is relatively well connected to urban 
Table 1 Sample overview

\begin{tabular}{llll}
\hline Gender & \multicolumn{3}{c}{ Role } \\
\hline Male & $36 \%$ & Head & $43.5 \%$ \\
Female & $64 \%$ & Spouse & $38 \%$ \\
Age & & 'child' & $18.5 \%$ \\
Under 24 & $15 \%$ & Location & \\
$25-34$ & $21.4 \%$ & Turkana & $38.8 \%$ \\
$35-44$ & $23.7 \%$ & Meru & $35 \%$ \\
$45-54$ & $14.9 \%$ & Makueni & $26.2 \%$ \\
Over 55 & $25 \%$ & Total sample & 538 \\
\hline
\end{tabular}

centres and has better potential for both agricultural production and opportunities for wage employment (Ministry of Agriculture Livestock and Fisheries, 2016). Besides the main food crops and livestock production, cash crops such as tea or coffee are produced (GOK \& IFAD, 2014). Within each county one sub-county was selected to represent the conditions outlined above. For Turkana, the sub-county included an irrigation scheme, so ensuring that farming was at least one option. In Meru, the sub-county was chosen based on its proximity to a secondary urban centre and the presence of large farms. In Makueni, the sub-counties were chosen to represent the medium distance to the capital city while being semi-arid.

During a second stage of sampling, ten villages were randomly selected within each county and from each village, ten households were randomly selected. Within each household the household head was interviewed. Additionally, we randomly selected either his/her spouse(s) or one of his/her children. This led to a total sample of 600 and, without replacement of unavailable respondents, this process led to 233 household heads, 204 spouses, 99 youths (age 16-35). Youth were underrepresented as not all households included children and several selected children were in school during the time of the interview. A sample overview by category is shown in Table 1.

\section{Survey Design}

As proposed in Mausch et al. (2018) we used a mixed qualitative/quantitative survey tool called SenseMaker®, whereby respondents share a short narrative in response to an initial prompting question and then interpret their own story using a set of quantitative assessment questions (Cognitive Edge 2014; Jenal 2016; Mausch et al. 2018; Polk 2017). An advantage of this methodology is that it does not restrict the respondent to categories of interest to the researcher and allows for a more open conversation about people's aspired future. Unlike more traditional qualitative methods, the respondent gives meaning to their narrative through 'self-signification', and is less prone to researcher bias. The tool has been used to explore drivers of child marriage (Bartels et al. 2018) and understand drivers of business relations (Deprez, n.d.), but the application to rural aspirations and agriculture is novel and therefore exploratory in nature. 
To start our survey, respondents were asked 'Imagine your life in 10 years' time, tell a story about how you got to that point from this present day?". This prompting question was purposefully open-ended, emotionally neutral and without reference to agriculture, to elicit an unrestricted response (Kay 2011). Additionally, we did not mention our interest in farming so as to further reduce bias and the potential for gaming. ${ }^{3}$ Respondents were then asked to interpret or 'signify' the meaning of their narrative using a set of assessment questions. These self-signification questions ${ }^{4}$ were developed from our theoretical framework (Fig. 1) to explore the main theoretical influences on livelihood strategies and aspirations, including community values, identity, motives and goals, support mechanisms, perceived risks and opportunities, and attitudes towards farming.

The self-signification process employed three basic types of questions, answerable as triads, dyads and stones. In triads, respondents are asked to interpret their narrative based on how it is balanced between three interrelated concepts. Each triad is displayed as a triangle where each apex represents one concept. Using a digital interface, respondents are asked place a ball within the triangle in the position that best represents their narrative. The closer the ball to any one corner, the stronger their story relates to the associated concept. This position within the triad yields three numerical values in relation to each apex (i.e. a three-part ratio). The sum of these three values is therefore equal to the whole ( $100 \%$ or 1$)$. For dyads, respondents are asked to rate their story along a sliding-scale between two opposing statements. Respondents can position their marker anywhere between these two labels to indicate their answer, leading to a $0-100$ scale. For stones, respondents are asked to place aspects of their story along two axes (i.e. a positive cartesian plane) allowing them to simultaneously rate two characteristics at the same time. The numeric values are standard $\mathrm{x}-\mathrm{y}$ coordinates that range from 0 to 100 for each category. The final section of the survey included several demographic questions to identify patterns across sub-populations such as men and women; young and old; and across different geographical locations.

Development of the survey instrument along the components outlined above followed a structured workshop approach involving several facilitated discussions between the research team, whose collective experience and expertise includes agricultural research, anthropology and the application of the SenseMaker ${ }^{\circledR}$ methodology and survey tool. The resulting survey instrument was then tested and refined

\footnotetext{
${ }^{3}$ To further reduce the potential for bias, the survey team was introduced under the label of Bangor University which has, unlike the CGIAR or World Agroforestry (ICRAF), no local associations with agriculture.

${ }^{4}$ The full survey instrument was implemented using the SenseMaker app and can be found in the Online Annex.
} 
with the team of enumerators recruited from the locations. The survey training and refinement was implemented with all teams jointly to ensure common understanding of the questionnaire, the approach and the concepts. Teams interviewed each other in their local languages to further refine the translation and ensure comparability within as well as across teams. ${ }^{5}$

Data collection was conducted in September 2018 using handheld tablets and the SenseMaker® data collection app. Each respondent was surveyed individually, and their story translated and transcribed into English by the enumerator before proceeding with the self-signification and demographic questions. Data analysis involved the visualisation of quantitative responses to examine emerging patterns in respondent perspectives and across sub-groups. Triad results were visualised as density plots and geometric means calculated using the "ggtern" package (Hamilton and Ferry 2018) in the R software environment (R Core Team 2020). Dyad and stones results were visualised as violin plots generated using the "vioplots" package (Hintze and Nelson 1998) in Stata (Winter and Nichols 2008). Narratives were then explored to help contextualise and facilitate interpretation of the quantitative results. For the topical analysis, all stories were reviewed and deductively coded into various categories based on their content (e.g. farming-related, non-farming-related or both). Finally, a simple linear regression analysis was conducted in Stata to assess how the various concepts captured using the self-signification questions interact and relate to aspirations.

\section{Aspirations: Directions, Drivers and Implications}

\section{Livelihood Strategies}

The narratives shared are short summaries of respondents' aspirational state 10 years from the interview. The most commonly mentioned topics are 'farming', 'business', 'family' and 'livestock' (Table 2), reflecting three main emerging themes from the narratives: investment in agricultural production, self-owned businesses and children's education. The terms 'farming' and 'livestock' are the main terms relating

\footnotetext{
5 We recognise the conceptual and linguistic uncertainties surrounding the local understanding of the concept of aspirations (for a discussion see Huijsmans et al. (2021)). However, the prompt question and subsequent follow-ups were couched in general terms only (see above). 'Aspiration' or other similar terms were not mentioned.
} 
Table 2 Topical focus of narratives across locations (\%)

\begin{tabular}{lcccc}
\hline & Total & Turkana & Meru & Makueni \\
\hline Farming & 60 & 40 & 66 & 82 \\
Business & 47 & 65 & 43 & 27 \\
Livestock & 44 & 41 & 45 & 49 \\
Plan & 37 & 31 & 35 & 49 \\
Family & 35 & 33 & 42 & 29 \\
Education & 29 & 27 & 36 & 22 \\
Water & 26 & 10 & 34 & 38 \\
Money & 25 & 26 & 24 & 26 \\
Achieve & 20 & 16 & 17 & 31 \\
Support & 14 & 17 & 10 & 13 \\
Employment & 13 & 11 & 15 & 14 \\
Improve & 12 & 11 & 15 & 9 \\
Dream & 10 & 4 & 22 & 4 \\
Continue & 9 & 12 & 4 & 11 \\
\hline
\end{tabular}

Columns do not add to 100 as multiple topics can be mentioned; 2 . Topics included here were mentioned in more than $10 \%$ of the cases

to agriculture. 'Business', however, is often used about multiple sectoral foci. For instance, many stories mention business in relation to non-agricultural enterprises, such as hair salons and rental houses, while others use this term in relation to agriculture, where people aspire to 'farming as a business'. Terms associated with children and education are mentioned in more than one third of the stories, indicating a strong focus on investment in children's futures. Positive forward-looking terms, such as 'achieve', 'better' or 'improve', also appear in many of the narratives, suggesting a degree of ambition among respondents.

The prevalence of these themes and the types of farm and non-farm livelihood activities mentioned varies across the three locations and likely reflects differences in their local agro-ecological context and off-farm opportunities. Box 1 provides a few exemplar narratives from across the three locations. In Meru, stories tend to focus on improving mixed farming, often involving investment in commercial dairy farming. Many stories also include non-agricultural aspirations such as running shops and rental houses. In Makueni, stories focus primarily on farming and activities such as planting fruit trees, digging farm ponds, buying water tanks, and growing higher-value crops such as vegetables. Some stories, however, mention nonagricultural activities such as owning hotels, shops and transportation businesses. In Turkana, far fewer stories mention farming compared to the other locations, and those that do tend to focus on livestock production. Non-farming-related aspirations include livestock trading, running small shops, weaving baskets, making mats and brooms and selling charcoal. 


\section{Box 1: Exemplar narratives}

Meru:

"I am currently in school and my aspiration in life is to become a businesswoman. I am a free minded person and I wouldn't like to be tied around or instructed around by someone. After school I will acquire basic skills on how to manage a business and other necessary knowledge about business and I will be good to go. I have not fully decided on what type of business but by then I will be decided." (Child, Female, under 24)

"I want to be through with educating my children then I am learning through a women's group how to keep dairy cows. My dream is to improve my farming through improved dairy farming. I want to be a large-scale milk producer." (Spouse, Female, 24-34)

"My home is located along Meru-Nanyuki highway, I would wish to take advantage of my location to start a business and since I am a carpenter by profession, I would open a hardware shop and also do farming as a side job. I will also consider constructing some rental houses and rent them out." (Head, Male, 24-34)

Makueni:

"[...] I am planning to see how I can get water and plant fruit trees. I want to be a large-scale fruit producer. Currently I have a small hotel and am hopeful in the next few years it will grow. I am a small-scale farmer but what I get as surplus I always sell." (Spouse, Female, 45-54)

"I imagine myself as a large-scale farmer. I want to also keep cattle and plant crops such as greengrams if I get enough water to irrigate them. I plan to achieve all this by working hard in my farm and saving money after selling some of my farm products." (Head, Female, 24-34)

"[...I] am planning to dig terraces in my land and trap water. Am planning to plant 1000 trees. I am also a small-scale farmer. I also work in Nairobi as a businessperson in shoes. I am also planning to involve in large scale poultry keeping. I will continue to keep a few livestock." (Head, Male, $35-44)$

Turkana:

"[...] I would like to still be taking my children through school and sustaining my family, to achieve this I would continue burning charcoal, making mats then sell them so as to raise money for school fees and when rains come, I usually plant something like wheat, which since it is usually in small amount it will help in terms of food supply but not business wise." (Head, Female, 35-44)

"I just want to get more animals and keep them till they become many and at that point I can sell them and solve whatever problem am going to encounter in my life. So yes, keeping livestock is what I will do." (Child, Female, 24-34)

"I am relying heavily on small jobs. Sometime this year an organisation came and gave me a small job in their office where I work as a cleaner. That job has helped me to cater for my needs and my family. As you can see, I can't say that I am going to depend on animals any longer because keeping animals has become a huge risk especially with the long droughts that we experience nowadays and also the animals have become prone to diseases and they die in large number living most people vulnerable to starvation. I also have a small farm along the river Turkwel where I plant during some months but not on a regular basis because again, farming is also not reliable". (Head, Male, 35-44)

The variation in agricultural focus across the three locations is also evident in the respondents' self-signification results. The assessment of the time spent farming in the future in Turkana is just under $40 \%$ (median). The other two counties are similar with median values just under $70 \%$ for Meru and just over $70 \%$ for Makueni. These reflect the current situation of agricultural focus in Meru and Makueni and pastoral lifestyles in Turkana. However, the median values hide large distributional differences of the answers. Figure 3 highlights that the relatively low median of the envisioned time spent farming in Turkana masks a bimodal distribution whereby substantial parts of the population would spend around $80 \%$ of their time with 
Fig. 3 Future share of time spent farming across locations

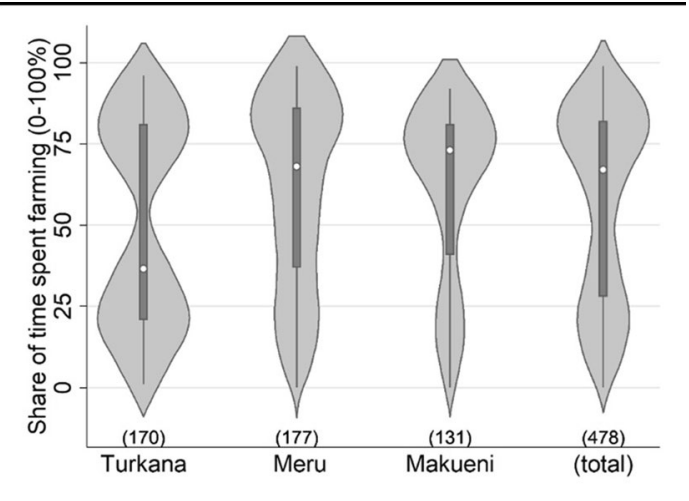

Note: Responses to the question "In the story shared... People spent all of their time farming (100) - People spent all their time on other things (0)"

farming activities, while another large part assumes they would only spend $20 \%$ of their time farming. Similarly, a relatively big share of respondents in Meru anticipate spending relatively little time farming as indicated by the fat tail of the distribution towards the bottom of the time shares. Makueni is the only county in which most people see themselves farming more than half of their time. This may be, at least partially, explained by the high number of female respondents in this site $(64 \%$ women) and the feminised nature of farm management in the county amid increasing male-outmigration (see Crossland et al. 2021).

The above observations may echo current income portfolios or signify new directions in income portfolios. We further analysed the narratives across categories that indicate directionality between e.g. intensifying current efforts or changing directions. Overall, most (53\%) of the narratives include a reference to continuation and/or improvements to current activities, while $46 \%$ of the narratives include distinct references to starting new endeavours. ${ }^{6}$ These trends are similar across all three locations with slightly fewer aspiring to start something new in Turkana (37\%) and slightly more in Meru (55\%) compared to Makueni (44\%).

Overall, within these rural communities most people have some relation to agriculture, but their aspirations are not all about farming.

\section{Aspiration Window}

In theory, the aspiration window is, to some degree, shaped by the opportunities people are aware of or encounter through community interactions. We thus expect that in places with more diverse opportunities the aspired future portfolios should also be more diverse. Figure 4(a) shows the perceived level of opportunities available to the respondents.

\footnotetext{
${ }^{6}$ Note that narratives can be in both categories if they mention intensification of some efforts as well as starting new endeavours.
} 


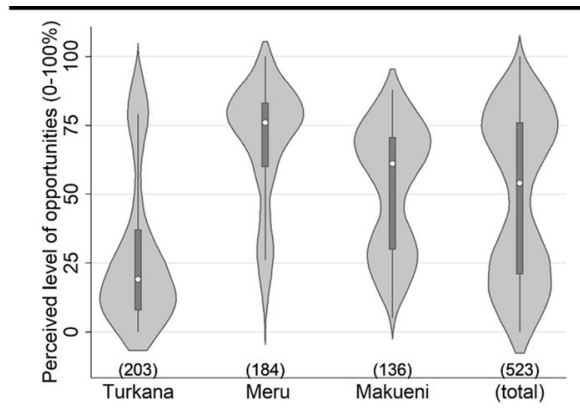

$\left(\mathrm{a}^{1}\right)$

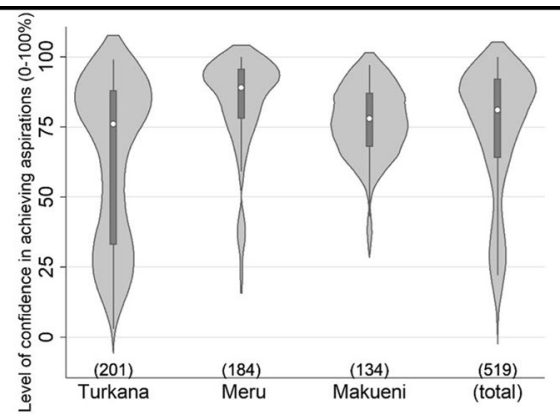

$\left(b^{2}\right)$

Notes: 1. Responses to the question "In the story shared, the world I live in... Has/had no opportunities (0) - Is filled with opportunities (100)"; 2. Responses to the question "In the story shared, the main character in the story felt... Confident they can achieve their goals (100) - Not confident that they can achieve their goals (0)"

Fig. 4 (a) Perceived level of opportunities across the three locations. (b) Stated level of confidence in achieving goals across the three locations

Across the three locations distinct patterns do emerge that align with prior expectation. The remote region of Turkana is dominated by traditional pastoral lifestyles and few opportunities are perceived by the respondents. Aside from a few governmental efforts and donor projects the economy is not very diverse or dynamic. In contrast, Meru county is more dynamic with some urban centres offering employment and business opportunities. Therefore, more opportunities are perceived by the respondents. Yet, most of them are still farming on small plots of land. Finally, Makueni county is intermediate with proximity to Nairobi but fewer options for agricultural production. These two drivers may be represented by the two-tailed distribution of the perceived opportunity space.

We further assumed that more opportunities would result in higher levels of confidence in achieving goals. Most respondents were confident that they would achieve their stated aspirations (Fig. 4(b)). The overall median was $81 \%$ and the county medians ranged from 61 to 89 . However, a strong cluster at the bottom end of the distribution in Turkana highlighted many people with little confidence in achieving their aspirations. Such diversity would be left out of many political processes when the majority is catered for and targeted but could be an important entry point to change the lives of a sub-section of the population. This might reflect some level of fatalism in Turkana where narratives reflecting low aspirations were relatively common.

The (perceived) level of opportunities appeared to have a strong influence on the direction of aspirations and the confidence in achieving them.

\section{Limits to Aspirational Pursuit}

To explore drivers of choices, respondents were asked to assess their narratives according to the basis for decisions made between the concepts of 'immediate needs', 'aspirations' and 'social obligations' - see Fig. 5. Overall, 'immediate needs' was the most important driver with a mean of $44.9 / 100$. In the absence 

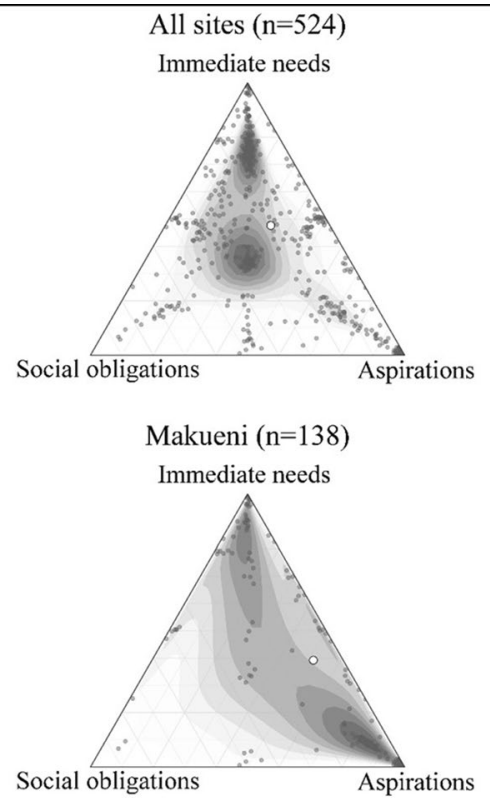
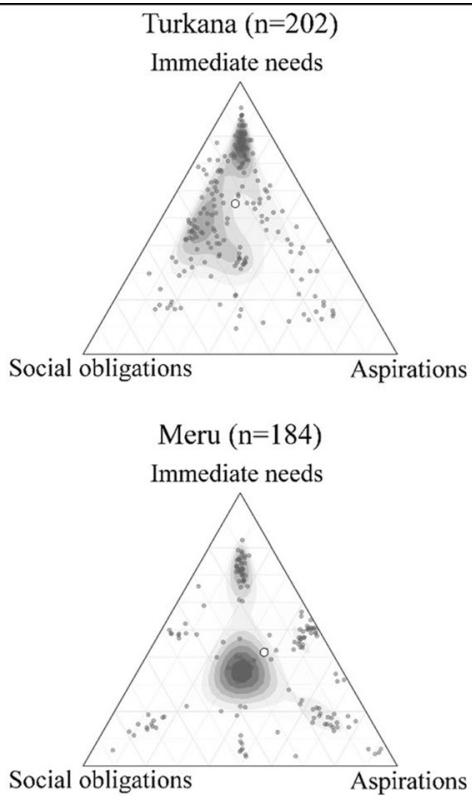

\begin{tabular}{lllll}
\hline \hline Basis of decisions made (Sample Means) & Turkana & Meru & Makueni & Total \\
\hline Social obligations & 25.1 & 24.8 & 12.0 & 21.5 \\
Immediate needs & 52.7 & 39.6 & 40.4 & 44.9 \\
Aspirations / motivation & 22.2 & 35.6 & 47.6 & 33.6 \\
\hline
\end{tabular}

Notes: Values across the three corners add to 100.

Fig. 5 Drivers of aspirational states

Table 3 Important aspects of aspirational states

\begin{tabular}{lllll}
\hline $\begin{array}{l}\text { Most important for the } \\
\text { story (Sample Means) }\end{array}$ & Turkana & Meru & Makueni & Total \\
\hline Fulfilment & 25.1 & 41.4 & 44.4 & 35.9 \\
Money & 58.4 & 47.6 & 43.3 & 50.7 \\
Social status & 16.5 & 11.0 & 12.3 & 13.5 \\
\hline
\end{tabular}

Values across the three corners add to 100

of social security and state provision of basic necessities, people are likely to be unable to move beyond the emergency mode of decision-making and pursue their aspirations. As expected, in Turkana immediate needs were even more important and very few people saw their choices being based on aspirations and, instead, immediate needs and social obligations were the main drivers. Responses from Meru were more balanced and highlight the strong diversity that can appear within a more complex context. Makueni county responses show yet another pattern with a big cluster forming around aspirations as the 
Table 4 Sources of identity

\begin{tabular}{lllll}
\hline $\begin{array}{l}\text { People identified with } \\
\text { (Sample Means) }\end{array}$ & Turkana & Meru & Makueni & Total \\
\hline Role in the community & 30.90 & 21.51 & 31.67 & 28.34 \\
Place they live & 31.84 & 32.68 & 24.22 & 29.92 \\
What they do & 37.26 & 45.82 & 44.11 & 41.74 \\
\hline
\end{tabular}

Values across the three corners add to 100

main driver for their choices but an almost equally strong group around immediate needs.

Similarly, most people emphasised money and fulfilment as the main factors behind their future narratives (Table 3 ). Social status was only considered important by a few respondents. For respondents from Turkana, the focus on money likely reflects the pressure of immediate needs.

Immediate needs and the importance of money suggest that choices are constrained and override the pursuit of aspirations - especially in Turkana. When basic needs are not fulfilled and people do not have sufficient income to pay for such things as school fees, they are forced to prioritise those needs over their aspirations. Especially in Turkana there was a sense or feeling of being trapped with few options except to 'muddle along' trying to survive. Yet there are also some people with clear aspirations and ambition. These observations suggest that in situations where income levels are very low, before developing programmes guided by aspirations, it may be important first to lift such constraints to allow people more freedom to follow their aspired future pathways.

Preconditions influence aspirations in more than one way. They determine the opportunity space, but they also limit the ability to pursue aspirations when immediate (monetary) needs are perceived as a more important decision-making criterion.

\section{Framing Aspirations}

Previous research has shown that Kenyan farmers' choices are driven by income but only as a means of achieving deeply held life goals (Okello et al. 2019) and framed and embedded in context and social dynamics (Dilley et al. 2021). Exploring these broader and less tangible factors that influence aspirations, people were asked to balance what they identify most with across 'where they live', 'what they do' and 'their role in the community'. This aimed to account for social drivers of aspirations and indicate whether farming could be a source of identity rather than solely an occupation (Verkaart et al. 2018). For people who base their identity on their occupation, the financial returns may be less important, and they would respond to support offerings in line with that occupation (Okello et al. 2019). Overall, occupation (what people do) appeared to provide identity for most people, although location and community still played a role (Table 4). Farming was not perceived purely as an occupation or simply a necessity but rather as a lifestyle for many. 


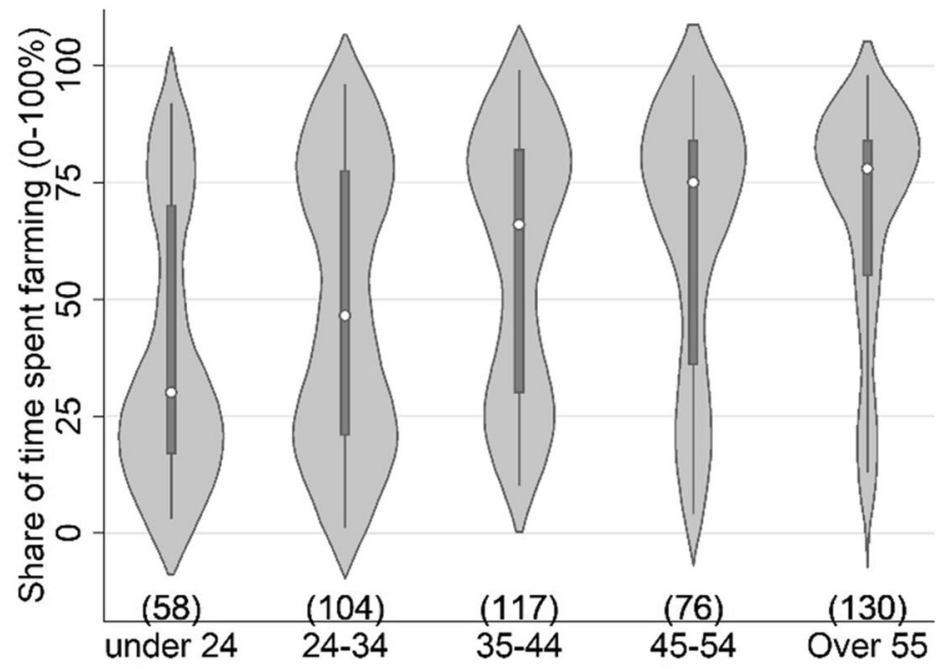

Notes: Responses to the question "In the story shared... People spent all of their time farming (100) - People spent all their time on other things (0)"

Fig. 6 Future share of time spent farming across age groups

\section{Path Dependency}

A clear shift in aspirations is seen across age categories (Fig. 6). The older the respondent, the more farming-focused the future becomes. The age group under 24 envisions spending little time farming and focuses on other income opportunities. Some differentiation appears within the groups from 24 to 44 where the median focus moves towards agricultural futures but there is more diversity with high numbers still focused on non-agricultural aspirations. The agricultural focus becomes dominant in the groups above 45 years of age. This observation is in line with previous results on youth aspirations that are mostly outside agriculture (Bezu and Holden 2014; Elias et al. 2018; Giuliani et al. 2017; Sumberg et al. 2017; Yeboah et al. 2020).

This observation may not only be driven by generational differences; older respondents are further along their life pathway and are therefore less likely or able to move away from agriculture albeit that circumstances may have been an important determinant of the outcome. Additionally, the sample was drawn from rural areas and so did not include older people who may have already moved out of agriculture and migrated to urban areas to pursue non-agricultural careers.

Furthermore, path dependency theory states that farmers tend to be locked into modes of operation until a trigger event forces or allows them to consider alternate pathways (Sutherland et al. 2012) which may be linked to their 
aspirations, hitherto constrained by context. This has temporal implications because younger people are less likely to have committed to pathways but then, throughout life, encounter points, such as the end of school/university, getting married or becoming parents, or in response to system shocks, where they reevaluate their current trajectory against their aspirations and potentially move down different paths. While the farming focus generally increases with age, this may partly be attributed to path dependency, although to fully assess this, a broader sample across rural and urban areas would be required.

\section{Relative Importance of Influences}

Finally, to assess how the various factors investigated above interact and relate to aspirations, we use three simple regression models to explore how the various concepts outlined above interact and associate with farming-related aspirations (1), aspirations to start something new (2) and decision-making being driven by aspirations (3). The three regressions combine the factors outlined above into three key variables that could provide entry points for policy and projects. They explore which factors are associated with (3) the stated pursuit of aspirations, which would explain (1) the aspiration to continue agriculture and which factors would hint at (2) the willingness to change and pursue new avenues. This analysis is exploratory and intended to shed light on potential starting points for more rigorous quantitative follow-up research and to generate testable hypotheses. The results (Table 5) are in line with the theoretical framework (Fig. 1).

For instance, needs-based decisions, as compared to aspiration-driven decisions, and general identification with people's community role, as compared to their occupation, were more likely associated with farming-related aspirations and less likely associated with aspiring to start something new. This supports the notion that resource constraints and a general sense of 'being a farmer' keep people on their current farming track and reduce the drive towards change. Older people were more likely to aspire to farming-based futures and less likely to start something new or make choices based on their aspirations. Instead, they develop aspirations for their children. This may reflect some degree of path dependency. Similarly, as expected, more time spent farming is associated with having farming-based future aspirations. Lastly, study site has a strong influence on both aspirational focus and self-assessment responses. Makueni respondents were more, and Turkana residents less likely to aspire to farming-based futures as compared to respondents from Meru. In addition, Makueni- and Turkana-based respondents were less likely to start something new which was possibly driven by a proximity to broader non-farm opportunities in Meru. Finally, compared to Meru, Turkana was less likely to share narratives based on aspirations, while Makueni was more likely to be driven by their aspirations. 
Table 5 Exploratory regression to test relative importance of influences

\begin{tabular}{|c|c|c|c|c|c|c|}
\hline \multirow{4}{*}{$\begin{array}{l}\text { Dependent Variable } \\
\text { Model } \\
\text { Variables }\end{array}$} & \multicolumn{2}{|l|}{ (1) } & \multicolumn{2}{|l|}{ (2) } & \multicolumn{2}{|l|}{ (3) } \\
\hline & \multicolumn{2}{|c|}{ Farming related } & \multicolumn{2}{|c|}{ Start something new } & \multicolumn{2}{|c|}{ Decision aspirations } \\
\hline & \multicolumn{2}{|l|}{ logit } & \multicolumn{2}{|l|}{$\operatorname{logit}$} & \multicolumn{2}{|l|}{ OLS } \\
\hline & Coef & $\mathrm{P}>|\mathrm{z}|$ & Coef & $\mathrm{P}>|\mathrm{z}|$ & Coef & $P>|t|$ \\
\hline Obligation decision & 0.014 & 0.122 & -0.009 & 0.182 & & \\
\hline Needs decision & 0.017 & 0.009 & -0.011 & 0.025 & & \\
\hline Aspiration decision & (omitted) & & (omitted) & & & \\
\hline Maximise fulfilment & -0.011 & 0.402 & 0.001 & 0.906 & -0.151 & 0.162 \\
\hline Maximise money & -0.001 & 0.948 & 0.009 & 0.328 & -0.265 & 0.010 \\
\hline maximise status & (omitted) & & (omitted) & & (omitted) & \\
\hline Identify community & 0.013 & 0.071 & -0.013 & 0.024 & 0.170 & 0.009 \\
\hline Identify place & -0.003 & 0.587 & -0.004 & 0.388 & (omitted) & \\
\hline Identify do & (omitted) & & (omitted) & & 0.098 & 0.076 \\
\hline Time spending farming & 0.025 & 0.000 & -0.001 & 0.763 & -0.070 & 0.107 \\
\hline Perceived opportunities & 0.003 & 0.003 & -0.006 & 0.166 & 0.137 & 0.005 \\
\hline Confidence achieving goals & 0.022 & 0.000 & 0.007 & 0.202 & 0.157 & 0.006 \\
\hline Age (categories) & 0.358 & 0.001 & -0.217 & 0.016 & -2.551 & 0.008 \\
\hline Turkana & -0.302 & 0.456 & -0.899 & 0.011 & -9.047 & 0.019 \\
\hline Makueni & 1.245 & 0.003 & -0.646 & 0.031 & 16.939 & 0.000 \\
\hline Meru & (omitted) & & (omitted) & & (omitted) & \\
\hline Starting something new & & & & & 5.455 & 0.023 \\
\hline Farming related aspiration & & & 1.032 & 0.000 & -8.127 & 0.006 \\
\hline Non-farming-related aspiration & & & 0.511 & 0.036 & 0.562 & 0.832 \\
\hline Constant & -4.203 & 0.004 & 0.630 & 0.584 & 39.385 & 0.001 \\
\hline $\mathrm{N}$ & 428 & & 428 & & 428 & \\
\hline (Pseudo) $\mathrm{R}^{\wedge} 2$ & 0.2373 & & 0.0868 & & 0.3206 & \\
\hline Log likelihood & -195.1 & & -269.38 & & & \\
\hline
\end{tabular}

\section{Aspirations as Potential Levers for Change}

The rural development debate has been discussed and theorised from various vantage points. Our approach of combining unrestricted aspiration narratives and respondents' interpretations offered novel insights into the diversity of aspirations in rural areas and thereby potential levers for change. While highlighting the need for more integrated strategies across sectors, agricultural support especially could benefit from a more detailed consideration of aspirations in the development and delivery of innovations. Explicit understanding of aspirations and the direction of envisioned change also has implications for information gathering and processing that could improve the relevance of support mechanisms for rural populations. Advances in the methodological approach and the resulting understanding of aspirations would lend further depth to the indicative implications of our results as outlined below. 


\section{Challenging Target Group Assumptions}

One key insight from the aspirational narratives is that while all households were involved in farming, only 65.8\% (354) of the respondents shared farming-related narratives. These households would be the primary target group for projects attempting to support rural development through agricultural support. Within this sub-group, another $65.3 \%$ (231) aspire to continue or improve their current activity and do not aspire to start new activities. Therefore, in our sample, interventions that target optimization of current farming systems would meet a naturally receptive population of 231 out of 538. Attempting to introduce a new activity in a location to improve peoples' livelihoods would have a naturally receptive target population of only 123 of 538 people - those that focus on agriculture and plan to start new activities. In line with Kihoro et al. (2021) for the case of Tanzanian dairy producers, this changes potential targets for dissemination efforts significantly from the current mainstream assumption that all households are farming-focussed and are therefore interested in farming innovations. It should also be recognised that aspirations are likely to vary within the household and that some members may wish to engage and invest in farming even when others look to step out (Crossland et al. 2021). Improving the understanding of aspirations within target locations and their interand intra-household variation would influence project design approaches as well as assessments of success.

\section{Re-defining Success}

Rural development could benefit from the consideration of aspirations by providing a grounded and localised framing of success. Predefined notions of what is achievable or desirable from an outside perspective or based on politically defined global targets are unlikely to match people's visions and desires and thereby are likely to be met with less enthusiasm. Our results and experiences with SenseMaker® highlight the many influences and complexities of interactions that enmesh with people's envisioned futures. This complexity means that engaging with aspirations and locally defined notions of success would require in-depth background work and robust theorization of foundations, entry points and pathways. Subsequently, theories of change are likely to become more complex and less static.

\section{Dynamics of Aspirations}

According to path dependency theory, people are more receptive to changes in their pathways when trigger events force them to re-evaluate their activities. These trigger events can be both acute (e.g. end of school) and chronic (i.e. adjustment of practice over time in response to climate change) and do not only have negative implications. These events could offer opportunities to stimulate contemplation of a broader set of options that people may have but do not normally consider. It is at these moments that farmers focus on their options. The start of a conversation about aspirations and future states could constitute a positive shock event and trigger new thoughts about 
strategies and trajectories. Testing this hypothesis could offer novel entry points for rural development that might overcome the inertia of the daily struggle to meet immediate needs.

\section{Opportunities to Aspire}

Farming related aspirations are associated with a greater perception of opportunities and a greater confidence in achieving goals. Widening opportunity space as well as better identification and dissemination of available opportunities could be a key leverage point for rural development initiatives and projects. Widening possibilities and highlighting options has the potential to change perceptions and inspire people to re-think their current strategies. However, efforts along these lines would have to be cognisant of recent findings which suggest that aspirations beyond the adjacent possible can lead to adverse outcomes and fatalistic behaviour (Galiani et al. 2018; Genicot and Ray 2020). Facilitating broader opportunities spanning agricultural and non-agricultural options would require coordination across a wider range of agencies to be successful. In line with Woltering et al. (2019), this points to the need to design programmes and support channels that are integrated across multiple agencies in order to offer a wide range of options across different crops, farming systems, business support services and others. Within the agricultural portfolio, this has been conceptualised as "options by context" (Sinclair and Coe 2019) which could be expanded to account for a wider range of income streams.

\section{New Approaches to Targeting}

Where immediate needs are no longer restricting the ability to pursue aspirations, what could offer promise is a change in the approaches to targeting. What we mean here is letting rural people choose their preferred support mechanisms from a much wider range of options. This implies changes to the focus of, and research on, rural development approaches. Jointly assessing agricultural and non-agricultural aspirations could generate 'scoping' insights prior to project design and could be integrated into existing survey tools. The integration of aspiration assessments with a more detailed household survey could prove especially insightful regarding the interactions between current context and strategy with future aspirations - accounting for those at individual, household and community level.

\section{Refining Methods}

To be more cognisant of aspirations, our work has highlighted some promising entry points for future rural development strategies and initiates. However, our work has its limitations. The various influences on the formation of aspirations that our study has highlighted suggests that any resulting rural development initiative 
and strategies which sought to draw on aspiration in order to allow individuals to develop a broader view of livelihood options would require more targeted and detailed research and methods. Future research would benefit from a more nuanced consideration of cultural backgrounds that may influence aspirations. For instance, our attempts to sample regions with limited opportunities might have confounded remoteness with culture e.g. in Turkana where pastoralism is widespread. However, given that our prompt question was non-specific, any biases towards livestock would have shown up in the narratives - which was not the case. Use of SenseMaker® has allowed us to explore, in a preliminary way, people's aspirations and their drivers. Nevertheless, for a more nuanced understanding of these different levels of aspirations, more explicit prompting questions either in surveys or interviews could be useful in eliciting descriptions of the current state, the aspirations themselves, the pathway towards them as well as the reasons for them.

\section{Conclusions}

We argue that understanding the degree to which farming features in the aspirations of rural households has the potential to help explain (non)adoption of agricultural technologies. Both farming and off-farm opportunities could be actively showcased and brought into community narratives to allow people to broaden their aspiration window. What our work suggests is that-before we arrive on the scene-everyone's options are mediated by their context. The narrative we have developed here is that people are born into livelihood systems where agriculture plays an important role. One may not be $100 \%$ a farmer, but it is unlikely that one lives a life untouched by agriculture (e.g. LaRue et al. 2021; Verkaart et al. 2018). Agriculture is probably the default option or the fallback position in many instances. Where and how people grow up shapes the default opportunity space, defines options and thus affects aspirations. Any narratives around future aspirations are grounded in current realities and tend to represent a negotiated ground between individual, household and community drivers (Bennike et al. 2020). In contexts where agriculture is (perceived to be) both viable and profitable it is more likely to remain the majority aspiration. In situations where this is not the case, aspirations play out in more complicated ways and the pull of non-agricultural options is counteracted by limited capital and a sense of being forced into agriculture. It is not yet clear if the indicated shift towards agriculture for older people reflects a shift in an individual's aspiration as they age and as their opportunity space evolves (e.g. inherit land) or narrows (e.g. restricted by previous life events or being "trapped" in agriculture); or whether young people who aspire to move out of farming migrate, and are therefore not captured in our sample, while those who aspire to farm, stay and are surveyed.

The main conclusion is that aspirations are a highly complex concept. They differ widely across locations and people, they are framed and shaped by context, their pursuit depends on current status and resources. Better knowledge of aspirations does offer entry points for better rural development but their influence on people's choices will have to be investigated in more detail. The mixed method 
approach and SenseMaker ${ }^{\circledR}$ as a tool offers novel insights but likely needs to be complemented with more detailed quantitative data to make insights more rigorous and actionable. At the more strategic and practical level, agricultural and nonagricultural strategies and entry point considerations need to be jointly assessed and analysed in the context of, and based on, a strong voice of rural people who are ultimately affected and expected to benefit from any interventions.

Supplementary Information The online version of this article (https://doi.org/10.1057/s41287-02100398-w) contains supplementary material, which is available to authorized users.

Acknowledgements This work was undertaken as part of, and funded by, the CGIAR Research Program on Grain Legumes and Dryland Cereals (GLDC); initial parts of this work were undertaken as part of, and funded by, the CGIAR Research Program on Policy, Markets and Institutions (PIM) and supported by CGIAR Fund Donors.

Open Access This article is licensed under a Creative Commons Attribution 4.0 International License, which permits use, sharing, adaptation, distribution and reproduction in any medium or format, as long as you give appropriate credit to the original author(s) and the source, provide a link to the Creative Commons licence, and indicate if changes were made. The images or other third party material in this article are included in the article's Creative Commons licence, unless indicated otherwise in a credit line to the material. If material is not included in the article's Creative Commons licence and your intended use is not permitted by statutory regulation or exceeds the permitted use, you will need to obtain permission directly from the copyright holder. To view a copy of this licence, visit http://creativecommons.org/licen ses/by/4.0\%.

\section{References}

Appadurai, A. 2004. The capacity to aspire: Culture and the terms of recognition - GSDRC. In Culture and public action, ed. V. Rao and M. Walton, 59-84. Palo Alto: Stanford University Press.

Barrett, C.B., T. Reardon, and P. Webb. 2001. Nonfarm income diversification and household livelihood strategies in rural Africa: Concepts, dynamics, and policy implications. Food Policy 26: 315-331.

Bartels, S.A., S. Michael, S. Roupetz, S. Garbern, L. Kilzar, H. Bergquist, N. Bakhache, C. Davison, and A. Bunting. 2018. Making sense of child, early and forced marriage among Syrian refugee girls: A mixed methods study in Lebanon. BMJ Global Health 3: 1.

Bennike, R.B., M.B. Rasmussen, and K.B. Nielsen. 2020. Agrarian crossroads: rural aspirations and capitalist transformation. Canadian Journal of Development Studies 41: 40-56.

Bernard, T., and A.S. Taffesse. 2014. Aspirations: An approach to measurement with validation using ethiopian data. Journal of African Economies 23: 189-224.

Bezu, S., and S. Holden. 2014. Are rural youth in Ethiopia abandoning agriculture ? World Development 64: 259-272.

Borras, S.M.J., M. Edelman, and C. Kay. 2008. Transnational Agrarian movements: Origins and politics, campaigns and impact. Journal of Agrarian Change 8: 169-204.

Cognitive Edge. 2014. Using Sensemaker® to understand girls' lives: Lessons learnt from GirlHub.

Crossland, M., A.M. Paez Valencia, T. Pagella, K. Mausch, D. Harris, and L. Winoweicki. 2021. Women's changing aspirations amid male outmigration. Insights from rural Kenya. European Journal of Development Research. https://doi.org/10.1057/s41287-021-00362-8.

Deprez, S., n.d. Using self-signified micro-narratives to provide systematic and real- time feedback on inclusive business in smallholder supply chains.

Dilley, L., K. Mausch, M. Crossland, and D. Harris. 2021. What's the story on agriculture? Using narratives to understand farming households' aspirations in Meru, Kenya. European Journal of Development Research. https://doi.org/10.1057/s41287-021-00361-9.

Elias, M., N. Mudege, D.E. Lopez, D. Najjar, V. Kandiwa, J. Luis, J. Yila, A. Tegbaru, G. Ibrahim, L. Badstue, and E. Njuguna-mungai. 2018. Gendered aspirations and occupations among rural 
youth, in agriculture and beyond: A cross-regional prescriptive. Journal of Gender, Agriculture and Food Security 3: 82-107.

Ellis, F., and S. Biggs. 2001. Evolving themes in rural development 1950s-2000s. Development Policy Review 19: 437-448.

Ellis, F., and H.A. Freeman. 2004. Rural livelihoods and poverty reduction strategies in four African countries. Journal of Development Studies 40: 1-30.

Galiani, S., Gertler, P., and Undurraga, R. 2018. Aspiration adaptation in resource-constrainted environments (No. 24264), NBER Working paper series, NBER Working Paper Series. Cambridge.

Gassner, A., D. Harris, K. Mausch, A. Terheggen, C. Lopes, R. Finlayson, and P. Dobie. 2019. Poverty eradication and food security through agriculture in Africa: Rethinking objectives and entry points. Outlook on Agriculture 48 (4): 309-315.

Genicot, G., and D. Ray. 2020. Aspirations and economic behavior. Annual Review of Economics 12: $1-32$.

Giuliani, A., S. Mengel, C. Paisley, N. Perkins, I. Flink, O. Oliveros, and M. Wongtschowski. 2017. Realities, perceptions, challenges and aspirations of rural youth in aryland agriculture in the Midelt Province, Morocco. Sustainability 9: 1-23.

GOK \& IFAD. 2014. Upper Tana Natural Management Project: Baseline Survey Report.

Government of Kenya and Food and Agricultural Organization of United Nations. 2014. Seed security assessment in the South-Eastern Livelihood Zones of Kenya. Nairobi: FAO.

Haggblade, S., P. Hazell, and T. Reardon. 2010. The rural non-farm economy: Prospects for growth and poverty reduction. World Development 38: 1429-1441.

Hamilton, N.E., and M. Ferry. 2018. Ggtern: Ternary diagrams using ggplot2. Journal of Statistical Software 87: 3.

Harris, D. 2019. Intensification benefit index: How much can rural households benefit from agricultural intensification? Experimental Agriculture 55: 273-287.

Harris, D., and A. Orr. 2014. Is rainfed agriculture really a pathway from poverty? Agricultural Systems 123: 84-96.

Hintze, J.L., and R.D. Nelson. 1998. Violin plots: A box plot-density trace synergism. American Statistician 52: 181-184.

Huijsmans, R., N. Ansell, and P. Froerer. 2020. Introduction: Development, young people, and the social production of aspirations. European Journal of Development Research. 33: 1-15.

Jenal, M. 2016. A new framework for assessing systemic change in Katalyst: The pilot study in local agri-business network. Summary report Katalyst. https://www.enterprise-development.org/wpcontent/uploads/JenalKatalyst2016.pdf. Accessed July 15, 2020.

Kauffman, S.A. 1996. Investigations. London: Oxford University Press.

Kay, J. 2011. Obliquity: Why our goals are best achieved indirectly. London: Profile Books.

Kihoro, E.M., G.C. Schoneveld, and T.A. Crane. 2021. Pathways toward inclusive low-emission dairy development in Tanzania: Producer heterogeneity and implications for intervention design. Agricultural Systems 190: 103073.

LaRue, K., T. Daum, K. Mausch, and D. Harris. 2021. Who wants to farm? Answers depend on how you ask: A case study on youth aspirations in Kenya. European Journal of Development Research. https://doi.org/10.1057/s41287-020-00352-2.

Llewellyn, R.S., and B. Brown. 2020. Predicting adoption of innovations by farmers: What is different in smallholder agriculture? Applied Economic Perspectives and Policy 42: 100-112.

Macours, K., and Vakis, R. 2014. Changing Households' Investments and Aspirations through Social Interactions: Evidence from a Randomized Transfer Program, Policy Research Working Paper. Latin American And the Caribean.

Makueni County Government. 2013. First County Integrated Development Plan 2013-2017. GOK.

Mausch, K., D. Harris, E. Heather, E. Jones, J. Yim, and M. Hauser. 2018. Households' aspirations for rural development through agriculture. Outlook Agriculture 47 (2): 108-115.

Mercandalli, S. , Losch, B. (eds.), Belebema, M.N., Bélières, J.-F., Bourgeois, R., Dinbabo, M.F., Fréguin-Gresh, S., Mensah, C., and Nshimbi, C. 2020. Rural migration in sub-Saharan Africa: Patterns, drivers and relation to structural transformation. FAO, Rome, Italy.

Monechi, B., Â. Ruiz-Serrano, F. Tria, and V. Loreto. 2017. Waves of novelties in the expansion into the adjacent possible. PLOS ONE 12: 1-18.

Okello, J., Y. Zhou, I. Barker, and E. Schulte-Geldermann. 2019. Motivations and mental models associated with smallholder farmers' adoption of improved agricultural technology: Evidence 
from use of quality seed Potato in Kenya. European Journal of Development Research 31: 271-292.

Polk, R.A. 2017. A multimodal study on how embodiment relates to perception of complexity. Parkway: ProQuest.

R Core Team. 2020. R: A language and environment for statistical computing. R Foundation for Statistical Computing, Vienna, Austria. https://www.R-project.org/.

Ray, D. 2006. Aspirations, poverty, and economic change. In Understanding poverty, ed. A.V. Banjerjee, R. Benabou, and D. Mookherjee. Oxford: Oxford University Press.

Rigg, J. 2006. Land, farming, livelihoods, and poverty: Rethinking the links in the Rural South. World Development 34: 180-202.

Scoones, I. 2009. Livelihoods perspectives and rural development. Journal of Peasant Studies 36: 171-196.

Sinclair, F., and R. Coe. 2019. The options by context approach: A paradigm shift in agronomy. Experimental Agriculture 55: 1-13.

Sumberg, J., T. Yeboah, J. Flynn, and N.A. Anyidoho. 2017. Young people's perspectives on farming in Ghana: A Q study. Food Security 9: 151-161.

Sutherland, L.A., R.J.F. Burton, J. Ingram, K. Blackstock, B. Slee, and N. Gotts. 2012. Triggering change: Towards a conceptualisation of major change processes in farm decision-making. Journal of Environmental Management 104: 142-151.

Turkana County Government (n.d) County Integrated Development Plan (CIDP) 2013-2017. Turkana County Government.

Verkaart, S., K. Mausch, and D. Harris. 2018. Who are those people we call farmers? Rural Kenyan aspirations and realities. Development in Practice 28: 468-479.

Winter, N., and Nichols, A. 2008. VIOPLOT: Stata module to produce violin plots with current graphics. repec:boc:bocode:s456902.

Woltering, L., K. Fehlenberg, B. Gerard, J. Ubels, and L. Cooley. 2019. Scaling - from "reaching many" to sustainable systems change at scale: A critical shift in mindset. Agricultural Systems 176 (102652): 1-9.

World Bank. 2015. World Development Report 2015 - Mind. World Bankd Group, Washington D.C: Society and Behavior.

Yeboah, T., E. Chigumira, I. John, N.A. Anyidoho, V. Manyong, J. Flynn, and J. Sumberg. 2020. Hard work and hazard: Young people and agricultural commercialisation. African Journal of Rural Studies 76: 142-151.

Publisher's Note Springer Nature remains neutral with regard to jurisdictional claims in published maps and institutional affiliations. 